\title{
A Novel Robust Control Strategy For Grid-Connected PV Systems Based On Modified Direct Power Control
}

\author{
A.H. Azad \\ Department of Electrical Engineering \\ Arak University of Technology \\ Arak, Iran \\ a.azad@arakut.ac.ir \\ C. Zhang \\ Department of Electrical Engineering \\ Technical University of Denmark \\ Kgs. Lyngby, Denmark \\ chezh@elektro.dtu.dk
}

\author{
H. Shateri \\ Department of Electrical Engineering \\ Arak University of Technology \\ Arak, Iran \\ shateri@arakut.ac.ir
}

\author{
T. Dragičević \\ Department of Electrical Engineering \\ Technical University of Denmark \\ Kgs. Lyngby, Denmark \\ tomdr@elektro.dtu.dk
}

\begin{abstract}
This paper presented a distinct control strategy for a grid-connected PV system. The proposed control strategy includes a Beta algorithm for maximizing power extraction, an optimum PI controller for controlling the boost converter, and direct power control (DPC) based on modified sliding mode control (SMC) for controlling a three-phase grid-connected inverter. The proposed controller not only solves the issues of conventional DPC and SMC controllers (chattering of control input and variable frequency response), it also establishes a practical path for designing a robust controller in PV systems. On system parameter uncertainty and mismatch uncertainties, the proposed controller performs well. The proposed controller eliminates the necessity of any additional current control loops, resulting in a more straightforward system design and control process and a faster transient response.
\end{abstract}

Keywords - PV system, direct power control, sliding mode control, grid-connected inverter, predictive, robust control

\section{INTRODUCTION}

Renewable energy is now widely recognized as the most important alternative to fossil fuels for generating electricity. Solar energy has received a lot of interest because of its ease of production and accessibility [1-2].

In [3-4], a general classification of conventional control methods in this field is presented. In [5], to control a threelevel NPC grid-connected inverter, a novel voltage oriented control (VOC) strategy with PI controller is presented. Although simple to apply, PI controllers generally have low robustness on uncertainties. Sliding mode control (SMC) [6], model predictive control (MPC) [7-8], Neural Network (NN) [8], adaptive control [9], fuzzy logic control (FLC) [10], partial feedback linearization (PFL) [12], H-infinity [13], and the combination of them are proposed to improve robustness.

In [14], a new proportional-integral-resonant controllerbased direct power controller (DPC) with space vector modulation (SVM) is proposed to control a three-phase gridconnected inverter. The controller's main drawbacks are slow transient response, susceptibility to system parameter uncertainty, and stability constraints.

In [15], a different approach to direct power control based on a predictive controller is proposed. To control active and reactive power, optimal switching vectors (determined by cost function) are selected using the discrete system model's predicted voltage and current. Despite having a low THD current, this controller has a widespectrum harmonic. The control strategy presented in [16] is similar to [15], except that the nonlinear constraint term on the switching frequency is considered and modeled in the cost function.

In [17], a multi-loop current control using the SMC to control a grid-connected inverter with an LCL filter is proposed. The design complexity and the chattering of control input resulting from the sign function are the major disadvantages of this controller. In [18], an SMC controller is presented to control the grid current with a simplified PWM modulation. Hysteresis-Band (HB) used instead of the sign function to solve the chattering problem, which has led to some improvements in the results. In [19], a novel PMWSMC controller is proposed. The linearized model is proposed to control a three-phase grid-connected inverter with an LCL filter. This controller contains three loops, and also discrete state observer has been used to reduce voltage sensors. The harmonics injected into the grid by the proposed controller are better than hysteresis modulation based SMC controllers.

In [7], a distinct MPC-based control approach is utilized to reduce the output current ripples. The sliding mode observers estimate grid voltage with proposed predictive compensation. The proposed observer reduces the number of $\mathrm{AC}$ voltage sensors required, but it is complex to design. The sign function used by the sliding mode observer will cause chattering of control input.

In [20], a novel DPC control strategy is proposed that utilizes three decreased switching tables to control a gridconnected three-level neutral point clamped (3-Level NPC) inverter. In [6], a new DPC-SMC is proposed to control a three-phase on-grid inverter. The sliding surfaces defined to control injected active and reactive power into the grid. Despite the use of the sign function in the proposed controller, the chattering problem still exists. Generally, in sliding mode controllers, chattering caused by control input and mismatch uncertainty are primary issues.

In this paper, to address the above issues, a modified sliding mode control-based direct power control strategy is proposed to control the active and reactive power of a threephase grid-connected inverter with L filters in a PV system. First, accurate modeling of different parts of the PV solar system is provided, and the dc-link controller and extraction algorithm is defined. In the next step, after defining the sliding surface to control active and reactive power, the control laws determined, and the system's stability in the presence of uncertainties and mismatches is proved. Finally, to validate the efficacy and performance of the proposed controller, the simulation results are presented. 


\section{Mathematical Modeling OF System}

\section{A. $P V$}

An accurate single diode model, real data of temperature, and solar irradiation have been used to increase the system's accuracy [21]. The output power of solar modules $(P p v)$ can be calculated as follows:

$$
P_{P V}=N_{P} V_{P V} I_{p v}-N_{P} V_{P V} I_{s a t}\left[\exp \left(\frac{q V_{P V}}{k T_{a}(t) A_{i} N_{s}}\right)-1\right]
$$

where $V_{P V}, I_{p v}, I_{s a t}, N_{p}, N_{s}, q, k, A_{i}$ represented the output voltage and current of $\mathrm{PV}$, saturation current of each module, $N_{P V}$ is the number of each PV modules, $N_{s}$ is the number of cells in PV module, $T_{a}$ is ambient temperature, $q$ and $K$ are constant, $A_{i}$ is ideality factor. Also, to extract maximum power from the PV modules, the beta method (presented in [21]) has been used.

\section{B. Boost Converter}

A conventional boost converter is used in this case study. This converter is controlled by an optimized PI controller using PWM modulation [22].

\section{DC Link}

The dc-link current in abc-frame can be calculated as follows [23]:

$$
I_{d c}=u_{a} I_{a}+u_{b} I_{b}+u_{c} I_{c}
$$

Where $u$ is control vector ( 0 or 1$)$. The dc-link current in the stationary reference frame $(\alpha \beta)$ can be written using the Clark transform as follows:

$$
I_{d c}=\frac{3}{2}\left(u_{\alpha} I_{\alpha}+u_{\beta} I_{\beta}\right)
$$

\section{Grid-Connected Inverter}

Fig. 1 part (a) shows how the inverter used in this case study and part (b) shows the equivalent circuit. The dynamic equations of the grid-connected inverter in the $\alpha \beta$ frame are equals to [23-24]:

$$
U_{\alpha \beta}=L \frac{d I_{\alpha \beta}}{d t}+R I_{\alpha \beta}+V_{\alpha \beta}
$$

where $I_{\alpha \beta}$ and $V_{\alpha \beta}$ denote the output current and voltage of grid. $U_{\alpha \beta}$ is the inverter's output voltage, and $R, L$ are resistance and inductance of output filter.
The instantaneous active and reactive power injected into the grid in a balanced three-phase system in the $\alpha \beta$ frame can be calculated as follows [24]:

$S(t)=P+j Q=-\frac{3}{2} V_{\alpha \beta} \times I_{\alpha \beta}^{*}$

Eq. (4) can be rewritten as Eq. (5) and (6) [24]:

$P=-\frac{3}{2}\left(V_{\alpha} i_{\alpha}+V_{\beta} i_{\beta}\right)$

$Q=-\frac{3}{2}\left(V_{\beta} i_{\alpha}-V_{\alpha} i_{\beta}\right)$

According to Eq. (6) and (7), the instantaneous active and reactive power deviation is equal to:

$$
\begin{aligned}
& \frac{d P}{d t}=-\frac{3}{2}\left(V_{\alpha} \frac{d i_{\alpha}}{d t}+i_{\alpha} \frac{d V_{\alpha}}{d t}+V_{\beta} \frac{d i_{\beta}}{d t}+i_{\beta} \frac{d V_{\beta}}{d t}\right) \\
& \frac{d Q}{d t}=-\frac{3}{2}\left(V_{\beta} \frac{d i_{\alpha}}{d t}+i_{\alpha} \frac{d V_{\beta}}{d t}-V_{\alpha} \frac{d i_{\beta}}{d t}-i_{\beta} \frac{d V_{\alpha}}{d t}\right)
\end{aligned}
$$

By assuming a balanced three-phase system, Eq. (8) and (9) can be rewritten as follows:

$$
\begin{aligned}
& \frac{d P}{d t}=-\frac{3}{2 L}\left[\left(V_{\alpha}^{2}+V_{\beta}^{2}\right)-\left(V_{\alpha} U_{\alpha}+V_{\beta} U_{\beta}\right)\right]-\frac{R}{L} P-\omega Q \\
& \frac{d Q}{d t}=-\frac{3}{2 L}\left[V_{\beta} U_{\alpha}-V_{\alpha} U_{\beta}\right]-\frac{R}{L} Q+\omega P
\end{aligned}
$$

\section{Proposed Control Sterategy}

To control a three-phase grid-connected inverter in a PV system, a proposed control based on direct power control utilizing a modified sliding mode controller is given. Also, Space vector modulation has been utilized to address variable frequency response in conventional DPC control, which leads to simplicity in designing inverter output filters when solving this issue. Moreover, the proposed control strategy provides robust performance against solar irradiation variations, miss-match uncertainties, inductance changes, and measurement noises. In Fig. 2, an overall block diagram of the proposed controller is shown.

The next sections will cover sliding surfaces, control laws, and proof of the proposed controller's stability in the presence of uncertainties.

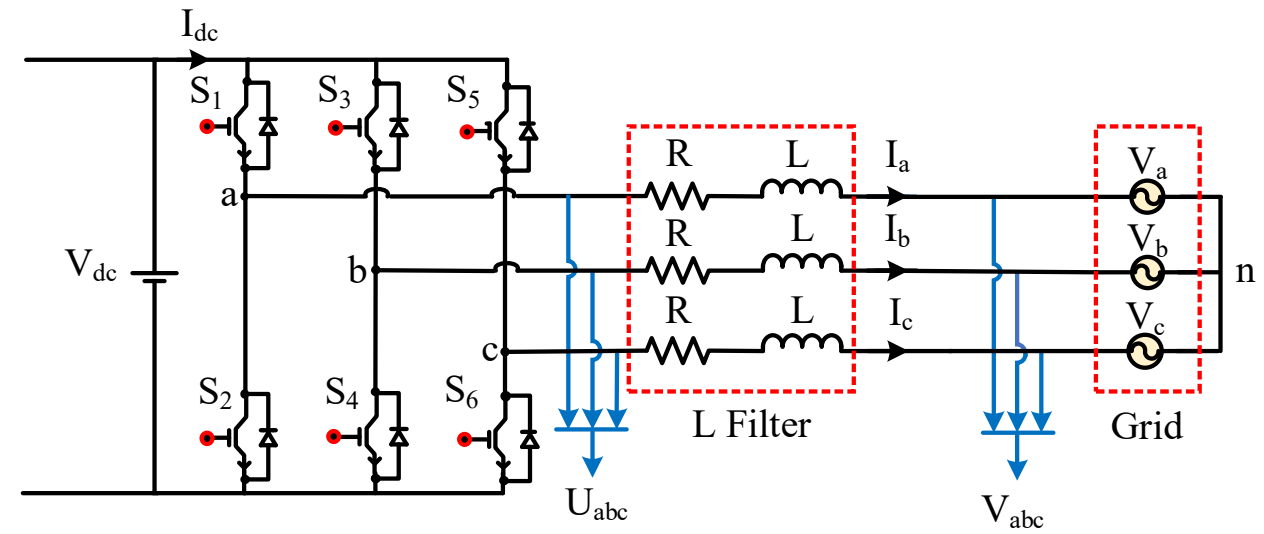

(a)

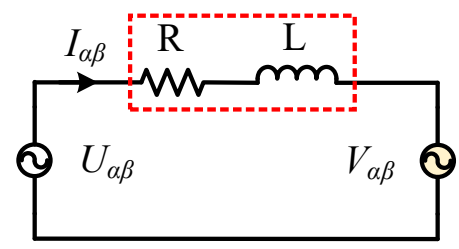

(b)

Fig. 1. (a) Three-phase grid-connected inverter with L filter (b) Equivalent circuit. 


\section{A. Sliding Surface}

The proposed sliding surfaces by the control objectives (tracking the reference values of active and reactive power) are defined as follows:

$$
\begin{aligned}
& S_{P}=e_{P}(t)+k_{p} \int_{0}^{t} e_{P}(\tau) d \tau-e_{P}(0) \\
& e_{P}(t)=P_{r e f}-P(t) \\
& S_{Q}=e_{Q}(t)+k_{Q} \int_{0}^{t} e_{Q}(\tau) d \tau-e_{Q}(0) \\
& e_{Q}(t)=Q_{r e f}-Q(t)
\end{aligned}
$$

where $S_{P}, S_{Q}$ denote the sliding surface of active and reactive power and. $P_{r e f}$ and $Q_{r e f}$ are the reference values of active and reactive power. $k_{P}$ and $k_{Q}$ are the positive coefficients that adjusted to improve transient response and minimize steady-state error.

When state variables reach the sliding surfaces and move along the surface:

$$
S_{P}=S_{Q}=\frac{d S_{P}}{d t}=\frac{d S_{Q}}{d t}=0
$$

When (14) was established, the active and reactive power accurately followed the reference values and were properly controlled. According to (14), the derivation of active and reactive power error on sliding surfaces can be written as follows:

$$
\begin{aligned}
& \frac{d e_{P}(t)}{d t}=-k_{p} e_{P}(t) \\
& \frac{d e_{Q}(t)}{d t}=-k_{Q} e_{Q}(t)
\end{aligned}
$$

\section{B. Sliding Mode Control Law}

The control variable must converge to the sliding surfaces in order to be controlled. The derivation of the sliding surfaces can be calculated as follows:

$$
\begin{aligned}
& \frac{d S_{P}}{d t}=\frac{d e_{P}(t)}{d t}+k_{p} e_{P}(t)=-\frac{d}{d t} P+k_{p}\left(P_{r e f}-P\right) \\
& \frac{d S_{Q}}{d t}=\frac{d e_{Q}(t)}{d t}+k_{Q} e_{Q}(t)=-\frac{d}{d t} Q+k_{Q}\left(Q_{r e f}-Q\right)
\end{aligned}
$$

(17) and (18) can be rewritten as:

$$
\frac{d S}{d t}=F+D U
$$

where $F=\left[\begin{array}{ll}F_{p} & F_{Q}\end{array}\right]^{T}, U=\left[\begin{array}{ll}U_{\alpha} & U_{\beta}\end{array}\right]^{T}$ and $D$ is the input matrix. In fact, the proposed sliding surfaces are influenced by inductance variations, sampling errors, and measurement noises; thus, the existing uncertainties are added to (18) in the form of a factor termed $\mathrm{H}$ :

$\frac{d S}{d t}=F+D U+H$

where $H=\left[\begin{array}{ll}H_{p} & H_{Q}\end{array}\right]^{T}$ is disturbance matrix. $H_{p}, H_{Q}$ are disturbances in the direction of active and reactive power, respectively.

The matrix $F$ and $D$ in (19) are defined as follows:

$$
\begin{aligned}
& F_{P}=\frac{3}{2 L}\left(V_{\alpha}^{2}+V_{\beta}^{2}\right)-\frac{R}{L} P-\omega Q+k_{p}\left(P^{*}-P\right) \\
& F_{Q}=\frac{R}{L} Q-\omega P+k_{Q}\left(Q^{*}-Q\right) \\
& D=-\frac{3}{2 L}\left[\begin{array}{cc}
V_{\alpha} & V_{\beta} \\
V_{\beta} & -V_{\alpha}
\end{array}\right]
\end{aligned}
$$

A Model Reference Adaptive Controller based on PI (MRAC-PI) is used as input [28]. Using the proposed controller as input while fixing chattering problems also eliminates the problems caused by the unmodeled high frequencies of conventional controllers in transient states. It also solves the issues of hidden instabilities due to the presence of discontinuous terms at the input of conventional sliding mode controllers (e.g., sign function). The proposed control input is equal to:

$U_{\text {new }}=-D^{-1}\left[F+H+u_{A-P I}\right]$

where $u_{A-P I}=\left[\begin{array}{ll}u_{A-P I, P} & u_{A-P I, Q}\end{array}\right]^{T}$ known as proposed input based on MRAC-PI. $u_{A-P I, P}, u_{A-P I, Q}$ are the input of the proposed MRAC-PI controller to control the active and reactive power, respectively. More information about the MRAC-PI controller can be founded in [25].

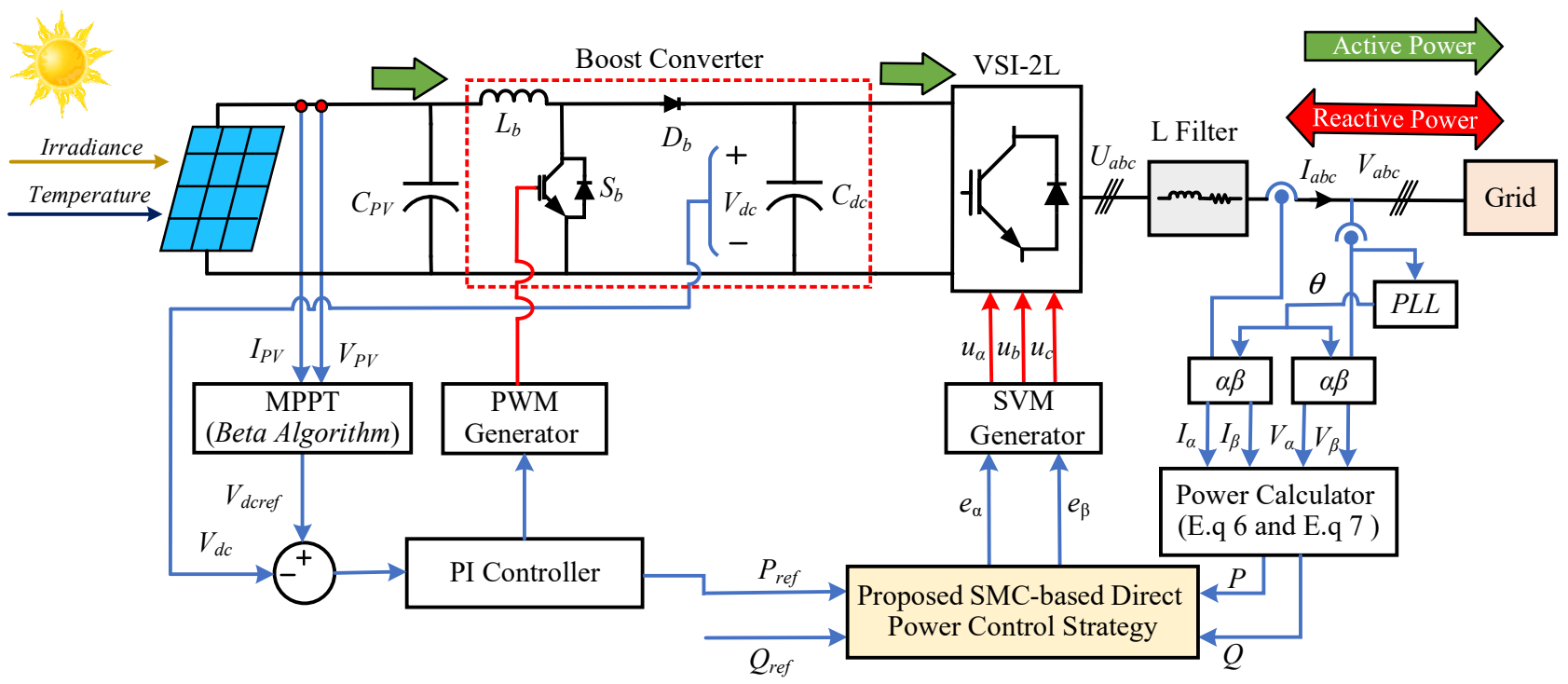

Fig. 2. The overall configuration of the proposed controller 
The matrix $u_{A-P I}$ in E.q (23) can be defined as follows:

$u_{A-P I, P}=k_{P P} S_{P}+k_{I P} \int S_{P}$

$u_{A-P I, Q}=k_{P Q} S_{Q}+k_{I Q} \int S_{Q}$

where $k_{p p}, k_{I P}, k_{P Q}, k_{I Q}$ denote proportional and integral coefficients used in the MRAC-PI controller are regulated for active and reactive power, respectively.

\section{Stablitiy}

If it is assumed that there are optimal PI coefficients $\left(k_{P P}^{r e f}, k_{I P}^{r e f}, k_{P Q}^{r e f}, k_{I Q}^{r e f}\right)$ for the proposed controller to monitor the active and reactive power, the proposed sliding surface will converge in a way as:

$$
S \dot{S} \leq-\xi|S|
$$

where $\xi$ is a positive constant. The error of the proposed controller parameters for monitoring the active and reactive power can be calculated as follows:

$$
\begin{aligned}
& \theta_{P X}=k_{P X}{ }^{*}-k_{P X} \\
& \psi_{I X}=k_{I X}{ }^{*}-k_{I X}
\end{aligned}
$$

where $\theta_{P X}, \psi_{I X}$ are the error of proportional and integral parameters of the proposed controller for monitoring active and reactive power, respectively. $X=\left[\begin{array}{ll}P & Q\end{array}\right]$ represents the active and reactive power injection to the grid. The Lyapunov function is defined in (27) to find control laws and prove the system's stability:

$$
V(S, \theta, \psi)=\frac{1}{2}\left[S^{2}+|\Omega|\left[c_{1 X}{ }^{-1} \theta_{P X}{ }^{2}+c_{2 X}{ }^{-1} \psi_{I X}{ }^{2}\right]\right]
$$

where $c_{1 X}, c_{2 X},|\Omega|$ represent constant and positive weight coefficient. In (27), the sliding surface and the error caused by the proposed controller are also considered.

In order to have a stable system, the derivation of Lyapunov function must be less than or equal to zero. The derivation of the Lyapunov function can be calculated as follows:

$$
\frac{d V}{d t}=\left(S \dot{S}+|\Omega|\left(c_{1 X}{ }^{-1} \theta_{P X} \dot{\theta}_{P X}+c_{2 X}{ }^{-1} \psi_{I X} \dot{\psi}_{I X}\right)\right)
$$

By replacing (24) and (26) in (28), the derivation of the Lyapunov function (27) can be rewritten as follows:

$$
\begin{aligned}
\frac{d V}{d t}= & \left(S \dot{S}+|\Omega|\left(c_{1 X}{ }^{-1} \theta_{P X} \dot{\theta}_{P X}+c_{2 X}{ }^{-1} \psi_{I X} \dot{\psi}_{I X}\right)\right) \\
= & S\left(F+D\left(-D^{-1}\left[F+H+u_{A-P I}\right]\right)+H\right) \\
& +|\omega| c_{1 X}{ }^{-1} \theta_{P X} \dot{\theta}_{P X}+|\Omega| c_{2 X}{ }^{-1} \psi_{I X} \dot{\psi}_{I X} \\
= & S\left(-k_{P X} S-k_{I X} \int S\right)+|\Omega| c_{1 X}{ }^{-1} \theta_{P X} \dot{\theta}_{P X} \\
& +|\Omega| c_{2 X}{ }^{-1} \psi_{I X} \dot{\psi}_{I X} \\
= & S\left(-\left(k_{P X}{ }^{*} S+k_{I X}{ }^{*} \int S\right)+\theta_{P X} S S+\psi_{I X} S \int S\right. \\
& +|\Omega| c_{1 X}{ }^{-1} \theta_{P X} \dot{\theta}_{P X}+|\Omega| c_{2 X}{ }^{-1} \psi_{I X} \dot{\psi}_{I X} \\
\leq & -\xi|S|+\theta_{P X} S S+\psi_{I X} S \int S+|\Omega| c_{1 X}{ }^{-1} \theta_{P X} \dot{\theta}_{P X} \\
& +|\Omega| c_{2 X}{ }^{-1} \psi_{I X} \dot{\psi}_{I X}
\end{aligned}
$$

The proposed control laws should be established and updated such that while controlling active and reactive power injected into the grid, it also leads to the system's stability.

$$
\left\{\begin{array}{l}
\dot{\theta}_{P X}=-\dot{k}_{P X}=-\frac{c_{1, X} \cdot S^{2}}{|\Omega|} \\
\dot{\psi}_{I X}=-\dot{k}_{I X}=-\frac{c_{2, X} \cdot S \int S}{|\Omega|}
\end{array}\right.
$$

By replacing (30) in (29), the derivation of the Lyapunov function can be rewritten as follows:

$$
\frac{d V}{d t} \leq-\xi|S|
$$

Therefore, the derivation of the Lyapunov becomes less than or equal to zero by implementing the proposed control input. According to the Lyapunov stability theorem, the errors of active and reactive power injected to the grid tend to zero, and also coefficients of the proposed PI adaptive controllers for regulating active and reactive power track the reference values. The proposed controller has good stability against uncertainties while solving the chattering problem at the control input; the upper bound of uncertainties does not need to be known, unlike conventional control strategies.

\section{Simulation AND RESUlts}

The parameters of the system and PV modules are given in Table I and Table II. Simulation in MATLAB has been used to verify the proposed control strategy. In Fig.3, the Power-Voltage curve of PV arrays utilized in this case study system is shown. The algorithm's optimum accuracy is verified by analyzing the maximum power extractable and the maximum power extracted by the algorithm (beta algorithm).

To analyze the proposed control system properly, the system results in solar irradiation uncertainties, and output inductor variation are evaluated.

TABLE I.

General Parameters of Test System

\begin{tabular}{cc|cc}
\hline Parameters & Values & Parameters & Values \\
\hline$V_{s}$ & $380 \mathrm{~V}$ & $P_{P V}$ & $5623 \mathrm{~W}$ \\
\hline$f_{\text {grid }}$ & $50 \mathrm{~Hz}$ & $L_{b}$ & $1 \mathrm{mH}$ \\
\hline$L_{\text {filter }}$ & $15 \mathrm{mH}$ & $C_{b}$ & $0.05 \mathrm{mf}$ \\
\hline$R_{\text {filter }}$ & $0.01 \Omega$ & $f_{b}$ & $6 \mathrm{kHz}$ \\
\hline$V_{d c}$ & $700 \mathrm{~V}$ & $C_{d c}$ & $2.5 \mathrm{mH}$ \\
\hline
\end{tabular}

TABLE II. PV ARRAY PARAMETERS

\begin{tabular}{cc|cc}
\hline Parameters & Values & Parameters & Values \\
\hline Irradiance & $1000 \mathrm{~W} / \mathrm{m}^{2}$ & $I_{S C}$ & $21.16 \mathrm{~A}$ \\
\hline Ambient Temp. Avg. & $298 \mathrm{~K}$ & $V_{M P P}$ & $287 \mathrm{~V}$ \\
\hline$V_{O C}$ & $353 \mathrm{~V}$ & $I_{M P P}$ & $19.8 \mathrm{~A}$ \\
\hline
\end{tabular}

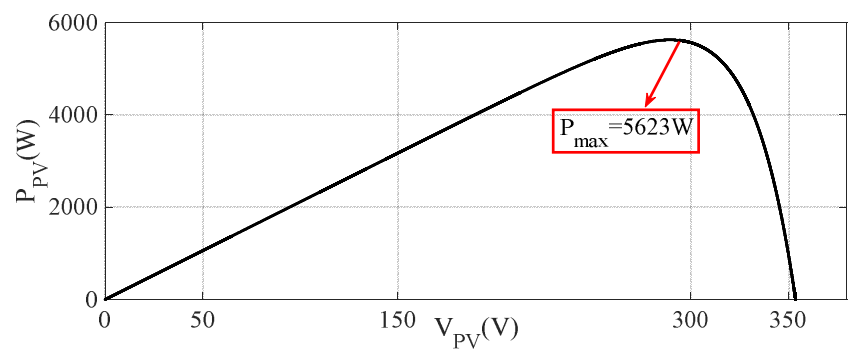

Fig. 3. Power-Voltage curve of PV arrays 


\section{A. System analysis under solar irradiation uncertainties}

Fig. 4 shows the dc-link voltage output of the proposed controller under different radiations. At $0.5 \mathrm{sec}$. the radiation changes from $1000 \mathrm{~W} / \mathrm{m}^{2}$ to $500 \mathrm{~W} / \mathrm{m}^{2}$, the system has demonstrated excellent performance versus radiation changes. Fig. 5 shows phase voltage-phase current (e.g., phase a), and Fig. 6 shows the power factor of the proposed controller. The proposed control has a robust performance on radiation changes and has a high power quality. Fig. 7 and Fig. 8 show the active power and the reactive power injected into the grid when the radiation changes in 1 second, from $1000 \mathrm{~W} / \mathrm{m}^{2}$ to $500 \mathrm{~W} / \mathrm{m}^{2}$. The results show excellent tracking of the reference values even though the radiation varies. The steady-state error of active and reactive power rapidly leads to zero.

\section{B. System analysis under inductane variations}

The dc-link voltage at a radiation $1000 \mathrm{~W} / \mathrm{m}^{2}$ and an $-25 \%$ uncertainty in the output inductor filter in 0.7 seconds to 0.9 seconds shows in Fig. 9. Active and reactive power injected to grid at $1000 \mathrm{~W} / \mathrm{m}^{2}$ is shown in Fig.10 and Fig.11, respectively, with a $-25 \%$ change in output filter inductor in 0.7 seconds to 0.9 seconds.

Despite the $-25 \%$ change in the output filter inductor, active and reactive power has not been disrupted, and the test system has not lost its stability. Between 0.7 seconds to 0.9 seconds, the steady-state error of active power and the reactive power increased slightly. After this time, the system has returned to regular operation. Despite severe uncertainty in the output filter inductor, the system has not lost its stability.

In this case, current THD is analyzed throughout time. In all of these scenarios, the current THD was less than 1.2 percent. Fig. 12 shows one of the THD current results. The proposed system has low THD and an excellent harmonic spectrum.

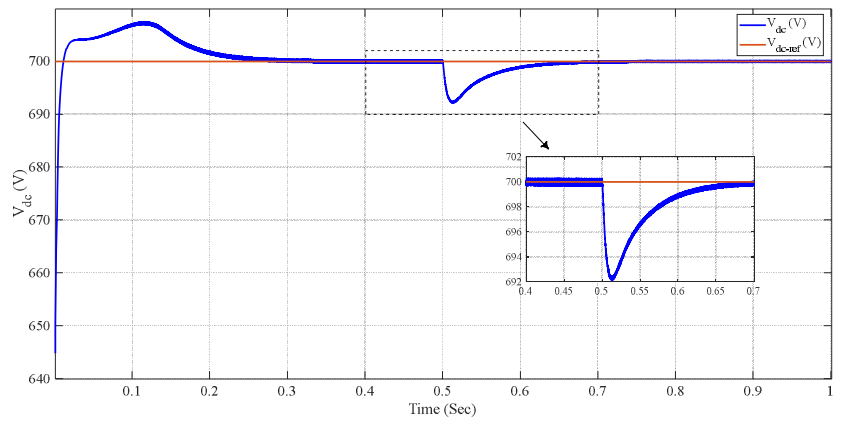

Fig. 4. Dc-link voltage during irradiation variations

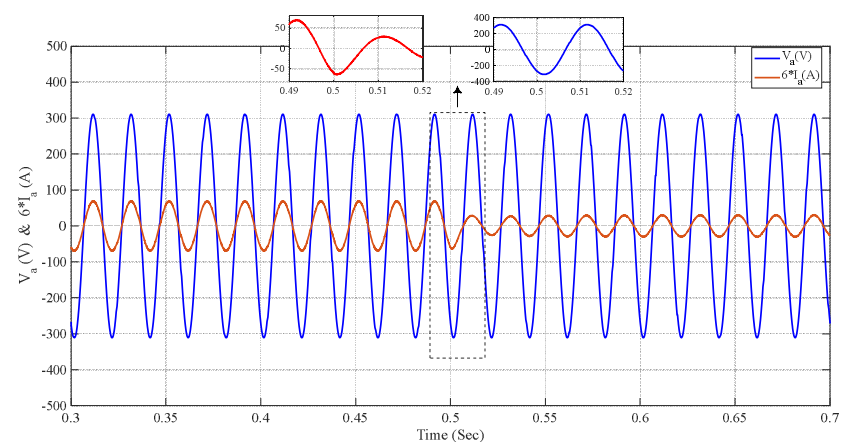

Fig. 5. Voltage and current of phase A during irradiation variations

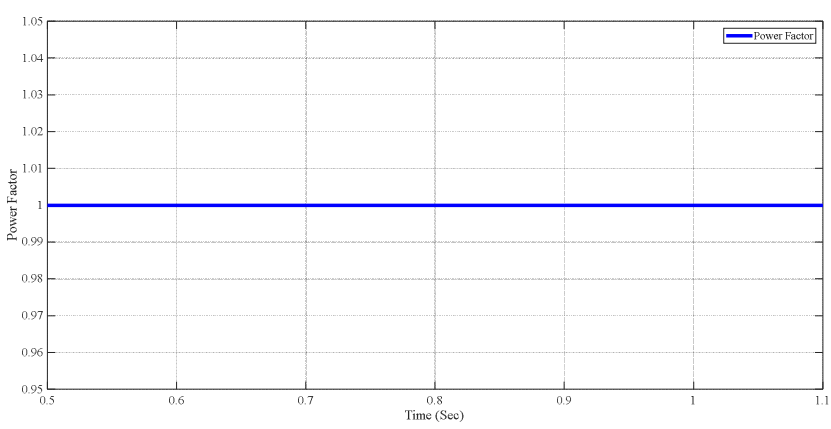

Fig. 6. Power factor during irradiation variations

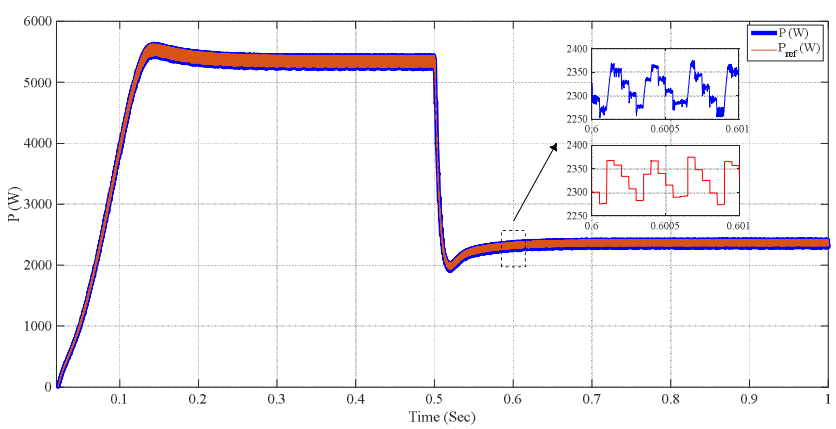

Fig. 7. Instantaneous active power during irradiation variations

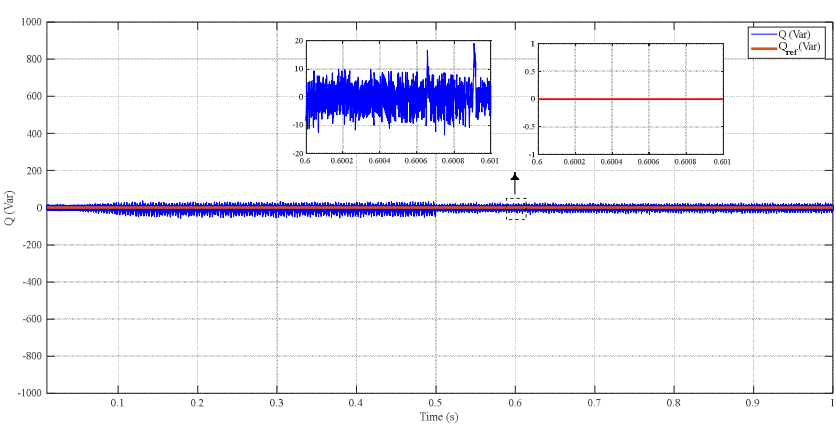

Fig. 8. Instantaneous reactive power during irradiation variations

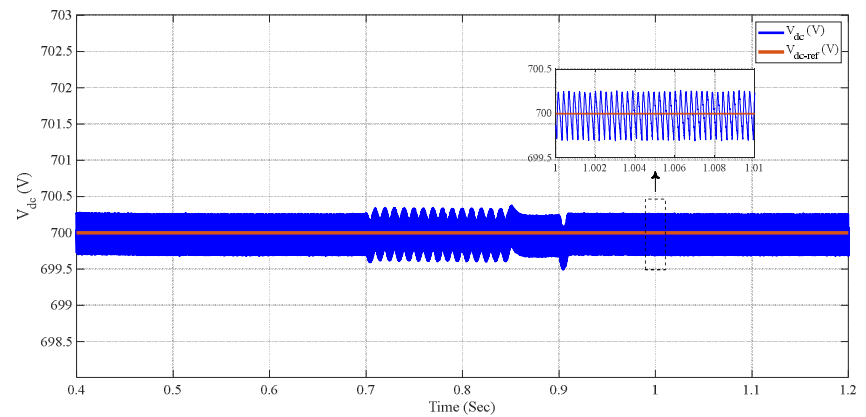

Fig. 9. Dc-link voltage during inductance variations

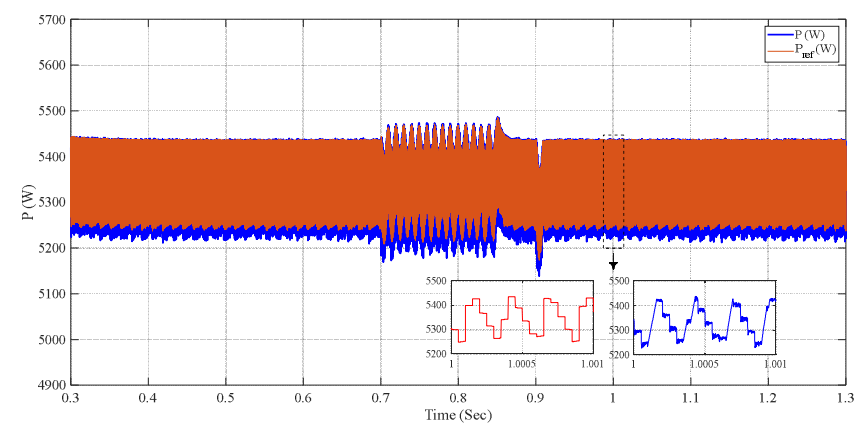

Fig. 10. Instantaneous active power during inductance variations 


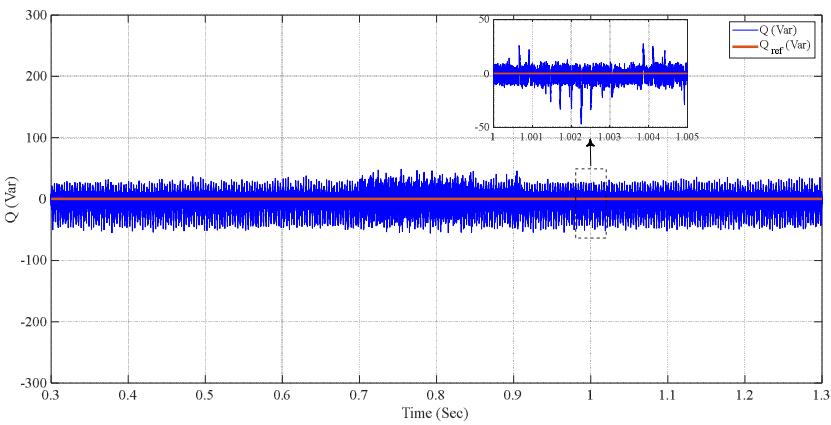

Fig. 11. Instantaneous reactive power during inductance variations

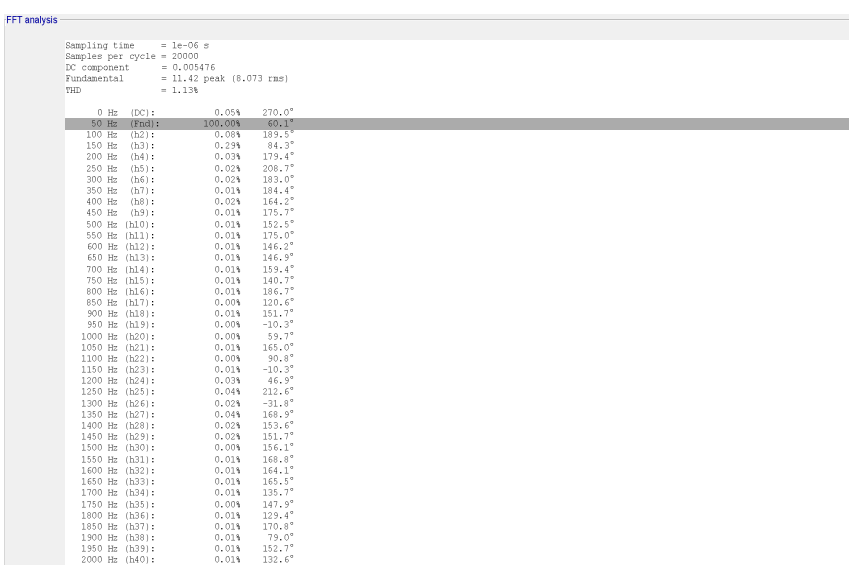

Fig. 12. THD of Phase A current during inductance variations

\section{CONCLUSION}

In this paper, a novel control strategy for a gridconnected PV system is proposed. A high-fidelity system model is utilized to improve the accuracy and efficiency of the proposed controller. Also, a specific theoretical route is presented for designing a robust controller. The direct power controller based on modified sliding mode control is used to control the grid-connected three-phase inverter.

The proposed controller has an excellent response in steady-state and transient states. Simulation results in MATLAB/Simulink verify theoretical proof of the system stability and robustness using Lyapunov function. Besides, the output current has an outstanding result and power quality (THD of output current always less than 1.2\%, which is less than the IEEE std.519) in the entire condition, including the presence of uncertainty (irradiation and inductance variations). The unit power factor can be achieved almost under all operating conditions.

\section{REFERENCES}

[1] Renewable Energy Policy Network for the 21st Century (Ren21), Renewables 2020 Global Status Report, 2020.

[2] A.H. Azad, V. Vahidinasab, H. Shateri, " Optimal Planning of a Stand-Alone Hybrid Energy Farm Encompassing Wind, PV, Diesel Generator and Storage Unit," 10th Smart Grid Conference (SGC), pp. 1-6, Dec. 2020.

[3] M.Y. Ali Khan, H. Liu, Z. Yang, X. Yuan, "A Comprehensive Review on Grid Connected Photovoltaic Inverters, Their Modulation Techniques, and Control Strategies", in Energies, vol. 13, Aug. 2020.

[4] H. Athari, M. Niroomand, and M. Ataei, "Review and Classification of Control Systems in Grid-tied Inverters,"in Renewable and Sustainable Energy Reviews, vol. 72, pp. 1167-1176, May 2017.

[5] G. Tsengenes and G. Adamidis, "A multi-function grid connected PV system with three level NPC inverter and voltage oriented control," in Solar Energy, vol. 85, no. 11, pp. 2595-2610, Nov. 2011.
[6] H. Özbay, S. Öncü, M. Kesler,"SMC-DPC based active and reactive power control of grid-tied three-phase inverter for PV systems," in International Journal of Hydrogen Energy, vol. 42, no. 28, Jul. 2017.

[7] L. Guo, N. Jin, Y. Li and K. Luo, "A Model Predictive Control Method for Grid-Connected Power Converters Without AC Voltage Sensors," in IEEE Transactions on Industrial Electronics, vol. 68, no. 2, pp. 1299-1310, Feb. 2021.

[8] T. Dragičević, "Model Predictive Control of Power Converters for Robust and Fast Operation of AC Microgrids," in IEEE Transactions on Power Electronics, vol. 33, no. 7, pp. 6304-6317, July 2018

[9] H. Kaushik, U. Kalla, B.Singh, "Modified neural network algorithm based control scheme of grid connected solar photovoltaic systems," in Electrical Energy System, Aug. 2020.

[10] R. V. Tambara, J. M. Kanieski, J. R. Massing, M. Stefanello, and H. A. Gründling, "A Discrete-Time Robust Adaptive Controller Applied to Grid-Connected Converters with LCL Filter,"in Journal of Control, Automation and Electrical Systems, vol. 28, no. 3, Mar. 2017.

[11] D. Lalili, A. Mellit, N. Lourci, B. Medjahed, and E. M. Berkouk, "Input output feedback linearization control and variable step size MPPT algorithm of a grid-connected photovoltaic inverter,"in Renewable Energy, vol. 36, no. 12, pp. 3282-3291,Dec. 2011.

[12] M. Mahmud, M. Hossain, H. Pota, and N. Roy, "Robust nonlinear controller design for three-phase grid-connected photovoltaic systems under structured uncertainties,"in IEEE Transactions on Power Delivery, vol. 29, no. 3, pp. 1221-1230,Apr. 2014.

[13] N. Yıldıran, E. Tacer " A New Approach to H-Infinity Control for Grid-Connected Inverters in Photovoltaic Generation Systems," in Electric Power Components and Systems, pp.1413-1422,Dec. 2019.

[14] L. Xiao, S. Huang and K. Lu, "DC-bus voltage control of gridconnected voltage source converter by using space vector modulated direct power control under unbalanced network conditions," in IET Power Electronics, vol. 6, no. 5, pp. 925-934, May 2013.

[15] S. Ouchen, A. Betka, S. Abdeddaim, and A. Menadi, "Fuzzypredictive direct power control implementation of a grid connected photovoltaic system, associated with an active power filter," in Energy conversion and management, vol. 122, pp. 515-525,Aug. 2016.

[16] J. Hu, J. Zhu, and D. G. Dorrell, "Model predictive control of gridconnected inverters for PV systems with flexible power regulation and switching frequency reduction," IEEE Transactions on Industry Applications, vol. 51, no. 1, pp. 587-594,Jun. 2014.

[17] R. P. Vieira, L. T. Martins, J. R. Massing and M. Stefanello, "Sliding Mode Controller in a Multiloop Framework for a Grid-Connected VSI With LCL Filter," in IEEE Transactions on Industrial Electronics, vol. 65, no. 6, pp. 4714-4723, Jun. 2018.

[18] N. Kumar, T. K. Saha and J. Dey, "Sliding-Mode Control of PWM Dual Inverter-Based Grid-Connected PV System: Modeling and Performance Analysis," in IEEE Journal of Emerging and Selected Topics in Power Electronics, vol. 4, no. 2, pp. 435-444, June 2016.

[19] H. Li, W. Wu, M. Huang, H. Shu-hung Chung, M. Liserre and F. Blaabjerg, "Design of PWM-SMC Controller Using Linearized Model for Grid-Connected Inverter With LCL Filter," in IEEE Transactions on Power Electronics, vol. 35, no. 12, pp. 12773-12786, Dec. 2020.

[20] Z. Ben Mahmoud, M. Hamouda and A. Khedher, "Direct power control with common mode voltage reduction of grid-connected three-level NPC inverter," in IET Power Electronics, vol. 12, no. 3, pp. 400-409, Mar. 2019.

[21] X. Li, H. Wen, Y. Hu, L. Jiang and W. Xiao, "Modified Beta Algorithm for GMPPT and Partial Shading Detection in Photovoltaic Systems," in IEEE Transactions on Power Electronics, vol. 33, no. 3, pp. 2172-2186, March 2018.

[22] F. Blaabjerg, Control of Power Electronic Converters and Systems, Academic Press, Mar. 2021.

[23] B. K. Bose, Modern Power Electronics and AC Drives, Prentice Hall PTR, 2002.

[24] M. Rashid, Power Electronics: Circuits, Devices \& Applications 4th Edition, Pearson, 2013.

[25] A.H. Azad, H. Shateri, "A Novel Control Strategy For On-Grid Photovoltaic Systems Based on Adaptive PI Control,"2019 Iranian Conf. on Renewable Energy \& Distributed Generation(ICREDG)", Tehran, Iran, pp. 1-6, Jun. 2019. 